\title{
COVID-Associated Respiratory Distress Syndrome (CARDS) in Pregnancy; What Makes it so Different?
}

\author{
Nader D. Nader ${ }^{(\mathbb{D}}$, Ata Mahmoodpoor ${ }^{2^{*} \mathbb{D}}$
}

$\mathrm{I}$ nfection with the novel coronavirus (nCOV-2) results in severe pneumonia known as COVID-19 disease. A good portion of infected patients develop severe form of acute respiratory distress syndrome (ARDS) that is associated with a high mortality rate. Almost all physicians around the world are familiar with the concept of ARDS, its diagnosis and treatment. However, COVID-19 associated respiratory distress syndrome (CARDS) especially in pregnant women has different features with many unanswered questions (1). Patients with CARDS although meet the Berlin criteria for ARDS, they generally present an atypical form of this syndrome. Gattinoni et al described two different types of CARDS as high elastance $(\mathrm{H})$ and low elastance $(\mathrm{L})$, which are usually distinguishable with computerized tomographic (CT) scanning (2). The almost constant presence of ground-glass opacity and crazy-paving pattern in the CT scan images of COVID-19 patients show an interstitial pneumonia in these patients (3). The ground-glass opacities can be due to the combination of mild edema of the alveolar septi, hyperplasia of the interstitium and partial filling of airspaces, although the crazy-paving pattern may correlate with intralobular and interlobular hyperplasia (Table 1) (4). It seems that lymphopenia, hypercoagulation and low grade inflammation is a classic description of this disease. So, endothelial activation, direct viral invasion of tissues and immunosuppression is a major reason for organ dysfunction in COVID-19 rather than hyperinflammation (5). Recent studies showed that inflammation imbalance and coagulopathy, clearly resulted in severity of disease in COVID-19 critically ill patients which predisposes to the development of microthrombosis, disseminated intravascular coagulation, and multi-organ failure evidenced in severe CARDS. Regarding the pathophysiology of this disease, it is clear that the effects of coagulation activation go beyond clotting and interaction between coagulation and inflammation can significantly affect disease progression and lead to poor outcome. So measuring local and

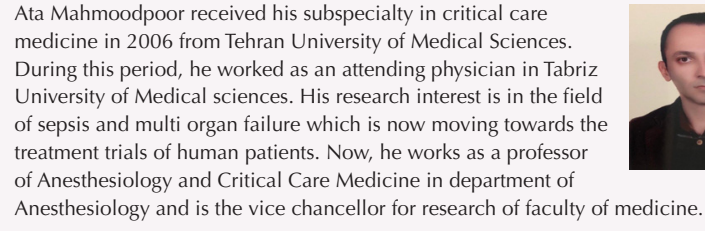

systemic inflammatory responses by corona virus can be used as to guide the standard treatment. Immune factors contributing to CARDS can be described as adaptive immune response to Corona virus, Extensive pulmonary macrophage activation and pulmonary immunovascular coagulopathy.

Regarding treatment in early stage, the key issue is the overcome the disrupted vasoregulation with improved oxygenation, early intubation, effective sedation, and/or paralysis which may interrupt that $(6,7)$. If lung edema increases in the patient with type $L$ because of the disease progression and/or Patient self-induced lung injury, the normal lung shrinks more, and the type $\mathrm{H}$ phenotype progressively develops. Progression to this type is meaning increased mortality (8).

Recent studies showed that immunosuppression, endothelial activation, and direct viral-mediated tissue damage, rather than hyperinflammatory injury, mediate COVID-induced organ dysfunction.

CARDS represents an ongoing global threat, as this virus family has the potential to mutate and infect non-immune populations. Physicians should be aware that CARDS in pregnancy is a serious complication of COVID-19, which requires early detection and appropriate management. We should emphasize that until we understand the complete nature of nCOV-2 infection and identify appropriate treatment strategies, advanced levels of supportive respiratory care remain the fundamental of managing CARDS patients. Although post-mortem examination is not generally carried out for safety reasons in known COVID-19 victims with high 
Table 1. Different characteristics of ARDS and CARDS

\begin{tabular}{|c|c|c|}
\hline & Acute Respiratory Distress Syndrome & COVID-Associated Respiratory Distress \\
\hline Risk Factors & $\begin{array}{l}\text { Higher APACHE-II, MODS, } \\
\text { Oxygenation index }\end{array}$ & $\begin{array}{l}\text { Older age, comorbidities like diabetes, hypertension and } \\
\text { cerebrovascular diseases }\end{array}$ \\
\hline Obesity & $\downarrow$ Mortality & $\uparrow$ Mortality \\
\hline Pregnancy & $\uparrow$ Mortality & $\downarrow$ Mortality \\
\hline Types & High elastance & $\begin{array}{l}\text { High elastance } \\
\text { Low elastance }\end{array}$ \\
\hline Radiologic findings & $\begin{array}{l}\text { Bilateral diffuse Patchy infiltration Comparable with } \\
\text { clinical findings }\end{array}$ & $\begin{array}{l}\text { Uni- or bi-lateral Ground glass opacification } \\
\text { Noncomparable with clinical findings }\end{array}$ \\
\hline Autopsy findings & $\begin{array}{l}\text { Diffuse alveolar damage, Pulmonary edema, Lymphatic } \\
\text { interstitial pneumonia }\end{array}$ & $\begin{array}{l}\text { Diffuse alveolar damage, pulmonary edema, vascular } \\
\text { damage (vasculitis), direct viral damage, thrombotic } \\
\text { microangiopathy with extensive fibrin deposition }\end{array}$ \\
\hline $\begin{array}{l}\text { Pulmonary vascular permeability index } \\
\& \text { extravascular lung water index }\end{array}$ & Decreased & May vary \\
\hline Inflammation & Hyperinflammatory & Hypo/Hyperinflammatory \\
\hline Shunt fraction & May vary & Increased \\
\hline $\begin{array}{l}\text { Therapeutics } \\
\text { ECMO }\end{array}$ & $\begin{array}{l}\text { Extracorporeal membrane oxygenation is considered as } \\
\text { rescue therapy ( } \downarrow \text { 60-day mortality with moderate } \uparrow \text { risk of } \\
\text { bleeding) }\end{array}$ & Extracorporeal membrane oxygenation has not been useful. \\
\hline Prone Position & Recommended as rescue therapy ( $\downarrow$ mortality) & $\begin{array}{l}\text { Recommended as early application of prone position (Co- } \\
\text { operative prone positioning) }\end{array}$ \\
\hline Corticosteroids & Low dose, short duration & High dose/low dose, short duration? \\
\hline NIPPV & Not recommended & Recommended to delay intubation \\
\hline $\begin{array}{l}\text { High-Flow } \\
\text { Nasal Oxygen } \\
\text { Immunotherapy }\end{array}$ & $\begin{array}{l}\text { Not useful } \\
\text { Not so effective based on the limited evidence }\end{array}$ & $\begin{array}{l}\text { Has been effective } \\
\text { A potentially strong therapeutic effect with ongoing trials }\end{array}$ \\
\hline Mortality & $30-40 \%$ & $>50 \%$ \\
\hline
\end{tabular}

virus load, autopsy findings could shed more light into the pathogenesis of this potentially fatal disease. Pregnant patients with COVID-19 show an ARDS phenotype, with heterogeneity in respiratory mechanics, aeration loss related to the degree of hypoxemia, and inter-individually variable recruitability (9). Finally CARDS in pregnancy consists of totally clinical, physiologic and immunologic profile compared to ARDS which should be considered in therapeutic and diagnostic approaches. It seems that CARDS reflects immunosuppression and features compatible with vascular disease instead of routine ARDS or cytokine storm syndrome.

\section{Ethical Issues}

Not applicable.

\section{Conflict of Interests}

None.

\section{Authors' contributions}

AM: hypothesis, manuscript drafting. NDN: manuscript editing. All authors read and approved the final format of manuscript.

\section{References}

1. Gattinoni L, Coppola S, Cressoni M, Busana M, Rossi S, Chiumello D. Covid-19 Does Not Lead to a "Typical" Acute Respiratory Distress Syndrome. Am J Respir Crit Care Med. 2020;201(10):1299-1300. doi:10.1164/rccm.202003-0817LE
2. Gattinoni L, Chiumello D, Rossi S. COVID-19 pneumonia: ARDS or not? Crit Care. 2020;24(1):154. doi:10.1186/s13054020-02880-z

3. Boraschi P. COVID-19 Pulmonary Involvement: Is Really an Interstitial Pneumonia? Acad Radiol. 2020;27(6):900. doi: 10.1016/j.acra.2020.04.010.

4. Guan CS, Lv ZB, Yan S, et al. Imaging Features of Coronavirus disease 2019 (COVID-19): Evaluation on Thin-Section CT. Acad Radiol. 2020;27(5):609-613. doi:10.1016/j. acra.2020.03.002

5. Leisman LE, Deustchman C, Legrand M. Facing COVID-19 in the ICU: vascular dysfunction, thrombosis, and dysregulated inflammation. Intensive Care Med 2020;46(6):1105-1108. doi: 10.1007/s00134-020-06059-6.

6. Kurdoğlu M, Khaki A. What is the current state of knowledge about the novel coronavirus infection during pregnancy? International Journal of Women's Health and Reproduction Sciences. 2020;8(2):110-111. doi: 10.15296/ijwhr.2020.17

7. Haghdoost SM, Khanbabayi Gol M. The necessity of paying more attention to the neurological and psychological problems caused by COVID-19 Pandemic during pregnancy. International Journal of Women's Health and Reproduction Sciences. 2020;8:243-244. doi: 10.15296/ijwhr.2020.40

8. Martini JJ, Gattinoni L. Management of COVID-19 respiratory distress. JAMA 2020;323(22):2329-2330. doi:10.1001/ jama.2020.6825

9. Grieco DL, Bongiovann Fi, Chen L, et al. Respiratory physiology of COVID-19-induced respiratory failure compared to ARDS of other etiologies. Crit Care. 2020;24:529. doi:10.1186/ s13054-020-03253-2.

(C) 2020 The Author(s); This is an open-access article distributed under the terms of the Creative Commons Attribution License (http:// creativecommons.org/licenses/by/4.0), which permits unrestricted use, distribution, and reproduction in any medium, provided the original work is properly cited. 